\title{
Magnetic resonance spectroscopy and diffusion tensor imaging in coma survivors: promises and pitfalls
}

\author{
Luaba Tshibanda ${ }^{1,2}$, Audrey Vanhaudenhuyse ${ }^{1}$, Damien Galanaud ${ }^{3}$, \\ Mélanie Boly ${ }^{1}$, Steven Laureys ${ }^{1, *}$ and Louis Puybasset ${ }^{4}$ \\ ${ }^{1}$ Coma Science Group, Cyclotron Research Center and Neurology Department, \\ University and University Hospital of Liège, Belgium \\ ${ }^{2}$ Department of Neuroradiology, University Hospital of Liège, Belgium \\ ${ }^{3}$ Department of Neuroradiology, Pitié-Salpêtrière Hospital, Paris, France \\ ${ }^{4}$ Department of Anesthesiology-Reanimation, Pitié-Salpêtrière Hospital, Paris, France
}

\begin{abstract}
The status of comatose patient is currently established on the basis of the patient-exhibited behaviors. Clinical assessment is subjective and, in $40 \%$ of patients, fails to distinguish vegetative state (VS) from minimally conscious states (MCS). The technologic advances of magnetic resonance imaging (MRI) have dramatically improved our understanding of these altered states of consciousness. The role of neuroimaging in coma survivors has increased beyond the simple evaluation of morphological abnormalities. The development of 1H-MR spectroscopy (MRS) and diffusion tensor imaging (DTI) provide opportunity to evaluate processes that cannot be approached by current morphologic MRI sequences. They offer potentially unique insights into the histopathology of VS and MCS. The MRS is a powerful noninvasive imaging technique that enables the in vivo quantification of certain chemical compound or metabolites as N-acetylaspartate (NAA), Choline (Cho), and Creatine (Cr). These biomarkers explore neuronal integrity (NAA), cell membrane turnover (Cho), and cell energetic function (Cr). DTI is an effective and proved quantitative method for evaluating tissue integrity at microscopic level. It provides information about the microstructure and the architecture of tissues, especially the white matter. Various physical parameters can be extracted from this sequence: the fractional anisotropy (FA), a marker of white matter integrity; mean diffusivity (MD); and the apparent diffusion coefficient (ADC) which can differentiate cytotoxic and vasogenic edema. The most prominent findings with MRS and DTI performed in traumatic brain-injured (TBI) patients in subacute phase are the reduction of the NAA/Cr ratio in posterior pons and the decrease of mean infratentorial and supratentorial FA except in posterior pons that enables to predict unfavorable outcome at 1 year from TBI with up to $86 \%$ sensitivity and $97 \%$ specificity. This review will focus on the interest of comatose patients MRI multimodal assessment with
\end{abstract}

\footnotetext{
${ }^{2}$ Luaba Tshibanda and Audrey Vanhaudenhuyse contributed equally to this work.

*Corresponding author.

Tel.: +32 436623 16; Fax: +32436629 46;

E-mail: steven.laureys@ulg.ac.be
} 
MRS and DTI. It will emphasize the advantages and pitfalls of these techniques in particular in predicting the coma survivors' outcome.

Keywords: traumatic brain injury; coma; diffusion tensor imaging; spectroscopy; prognosis; outcome

\section{Introduction}

Survivors of severe brain damage following traumatic brain injury (TBI), stroke, or anoxic/ hypoxic encephalopathy may remain in an altered state of consciousness during several years. TBI is the most frequent etiology of severe brain damage among young and middle-aged adults (as compared to stroke and tumors in elderly subjects; Katz, 1997), leading to up to $14 \%$ of subsequently permanently vegetative patients (Celesia, 1993; Jennett, 2005; Payne et al., 1996). However, in about $5-10 \%$ of these TBI patients, anatomical lesions detected by classical morphological MRI (sequences such as T2*, FLAIR, and diffusion) are unable to explain their clinical status and to give clue about their chance of recovery. These patients present significant problems concerning diagnosis and misdiagnosis, prognosis, and therapy (Andrews et al., 1996; Childs and Mercer, 1996; Schnakers et al., 2009). The announcement of an optimistic outcome will increase the commitment of the team, while a pessimistic prognosis risks demobilizing and jeopardizing the potential recovery of the patient. Questions about end of life, aggressive therapy, limitation of care, and euthanasia often arise in such cases and lead to passionate debates among the medical staff, and sometimes more widely in the media and society. Therefore, neuroimaging techniques should be used not only to evaluate structural abnormality and detect TBI complications but also to reliably show the extent of brain damage in a clinical diagnostic and a therapeutic way and lead to a better understanding of the behavioral observations. In this review, we discuss recent developments in the use of proton magnetic resonance spectroscopy (MRS) and diffusion tensor imaging (DTI) in the assessment of brain injury patients in particular after TBI due to the frequency of this etiology.

\section{Imaging protocols}

Magnetic resonance imaging (MRI) in coma survivors is routinely performed on $1.5 \mathrm{~T}$ or $3 \mathrm{~T}$ MR scanners. MRI assessment may often be limited by patient motion which can necessitate sedation; the risk of uncontrolled intracranial pressure occurring during the exam if performed when brain swelling is still present; unstable hemodynamic or respiratory condition, due to the limited monitoring available in the magnet; and artifacts generated by some metallic devices (most commonly intracranial pressure valves). In our view, a comprehensive patient MRI exploration should check both infra- and supratentorial structures, involved in arousal and awareness functions (Boly et al., 2008b). The ascending reticular activating system, located in the posterior part of the upper two-thirds of the brainstem is the primary arousal structure (Parvizi and Damasio, 2001; Plum and Posner, 1980). The evaluation of the patient's brain ability to generate awareness should include the assessment of the integrity of a large set of supratentorial structures, encompassing thalamus, basal forebrain, and fronto-parietal association cortices (Laureys et al., 1999; Parvizi and Damasio, 2001; Selden et al., 1998).

Classical morphological MRI was shown to poorly correlate with recovery of consciousness in severely brain-damaged patients. The fact that patients often develop progressive posttraumatic global brain atrophy (Table 1), despite the fact that initial morphologic imaging revealed only discrete findings or failed to show any pathology, also reflects the insufficiency of conventional imaging techniques to comprehensively evaluate the gravity of brain lesion in individual patients (Anderson et al., 1996; Gale et al., 1995; Gentry et al., 1988; Kelly et al., 1988). In particular, morphological MRI is not accurate for diagnosis 
Table 1. Prognosis values of structural magnetic resonance imaging, magnetic resonance spectroscopy, diffusion weighted imaging and diffusion tensor imaging in altered state of consciousness patients

\begin{tabular}{|c|c|c|c|c|c|}
\hline Authors & $\begin{array}{l}\text { Number of } \\
\text { patients }\end{array}$ & Diagnosis & Etiology & Interval & Main findings \\
\hline \multicolumn{6}{|c|}{ Structural magnetic resonance imaging } \\
\hline Firsching et al. (1998) & 61 & $\begin{array}{l}\text { Coma; } \mathrm{CGS} \leq 7 \\
(n=61)\end{array}$ & TBI & $<7 \mathrm{~d}$ & $\begin{array}{l}100 \% \text { of mortality with bilateral pontine } \\
\text { lesion, } 2 \% \text { with no brainstem lesion, } 8 \% \\
\text { with unilateral or midline mesencephalon } \\
\text { lesion, } 8 \% \text { with unilateral pons or medulla } \\
\text { oblongata lesion, and } 0 \% \text { with lesion of the } \\
\text { lower bilateral portions of medulla } \\
\text { oblongata }\end{array}$ \\
\hline Kampfl et al. (1998) & 80 & $\begin{array}{l}\text { Vegetative state; } \\
\text { CGS } \leq 8(n=80)\end{array}$ & TBI & $\begin{array}{l}50 \mathrm{~d}, \text { range } \\
42-56\end{array}$ & $\begin{array}{l}\text { 214-fold higher probability for not } \\
\text { recovering with lesions in the corpus } \\
\text { callosum and } 7 \text {-fold with dorsolateral } \\
\text { brainstem lesion }\end{array}$ \\
\hline Paterakis et al. (2000) & 24 & $\begin{array}{l}\text { Severe head injury; } \\
\text { GCS }<8(n=19) \\
\text { Moderate head } \\
\text { injury; GCS } 9-12 \\
(n=5)\end{array}$ & TBI & $<48 \mathrm{~h}$ & $\begin{array}{l}\text { Good recovery when hemorrhagic DAI } \\
\text { lesions; unfavorable outcome not } \\
\text { associated with isolated nonhemorrhagic } \\
\text { DAI lesions; } 100 \% \text { of unfavorable outcome } \\
\text { when subcortical gray matter injury; } \\
\text { subarachnoid hemorrhage not associated } \\
\text { with favorable and unfavorable outcome }\end{array}$ \\
\hline Carpentier et al. (2006) & 40 & $\begin{array}{l}\text { Severe TBI; GCS } \\
6 \pm 3(n=40)\end{array}$ & TBI & $17 \pm 11 \mathrm{~d}$ & $\begin{array}{l}\text { Number of brainstem lesions: } 4.3 \pm 3.3 \text { for } \\
\text { patients with GOS }=1-2,1.9 \pm 1.5 \text { for } \\
G O S=3,0.5 \pm 1.1 \text { for GOS }=4-5\end{array}$ \\
\hline \multicolumn{6}{|c|}{ Magnetic resonance spectroscopy } \\
\hline Choe et al. (1995) & 10 & $\begin{array}{l}\text { Closed head injury; } \\
\text { GCS 3-12 }(n=10)\end{array}$ & TBI & $132 \pm 134 \mathrm{~d}$ & $\begin{array}{l}\text { Fronto-parietal white matter: positive } \\
\text { correlation of NAA/Cr ratio with } \\
\text { emergence of vegetative state }\end{array}$ \\
\hline Friedman et al. (1999) & 14 & $\begin{array}{l}\text { TBI; GCS } 3-8 \\
(n=7), \text { GCS } 9-14 \\
(n=5), \text { GCS NA } \\
(n=2)\end{array}$ & TBI & $45 \pm 21 \mathrm{~d}$ & $\begin{array}{l}\text { Occipito-parietal white and gray matter: } \\
\text { patients with decreased NAA } \\
\text { concentration have poor overall cognitive } \\
\text { function at outcome }\end{array}$ \\
\hline Garnett et al. (2000) & 26 & $\begin{array}{l}\text { TBI; GCS } 3-8 \\
(n=9), \text { GCS } 9-15 \\
(n=17)\end{array}$ & TBI & $\begin{array}{l}12 \mathrm{~d}, \text { range } \\
3-35\end{array}$ & $\begin{array}{l}\text { Frontal white matter: GOS correlated with } \\
\text { NAA/Cr }(r=0.65) \text { and NAA/Cho ratio } \\
(r=0.58) ; \mathrm{GOS} \text { did not correlate with Cho/ } \\
\mathrm{Cr} \text { and } \mathrm{Ins} / \mathrm{Cr}\end{array}$ \\
\hline Sinson et al. (2001) & 30 & $\begin{array}{l}\text { TBI; GCS } 3-15 \\
(n=30)\end{array}$ & TBI & $\begin{array}{l}41 \mathrm{~d} \text {, range } \\
2-1129\end{array}$ & $\begin{array}{l}\text { Splenium: NAA/Cr ratio significantly lower } \\
\text { in patients with } \leq \mathrm{GOS}=1-4(1.24 \pm 0.28 \\
\text { NAA/Cr ratio) than GOS }=5(1.53 \pm 0.37 \\
\text { NAA/Cr ratio })\end{array}$ \\
\hline Uzan et al. (2003) & 14 & $\begin{array}{l}\text { Vegetative state; } \\
\text { GCS } 4-7(n=14)\end{array}$ & TBI & $193 \pm 19 d$ & $\begin{array}{l}\text { Thalamus: lower NAA/Cr ratio in } \\
\text { permanent vegetative patients }(1.17 \pm 0.25) \\
\text { than patients who recovered }(1.8 \pm 0.26, \\
p<0.001) \text {; Cho/Cr ratio did not permit } \\
\text { outcome differentiation }\end{array}$ \\
\hline Carpentier et al. (2006) & 40 & $\begin{array}{l}\text { Severe TBI; GCS } \\
6 \pm 3(n=40)\end{array}$ & TBI & $17 \pm 11 \mathrm{~d}$ & $\begin{array}{l}\text { Brainstem: NAA/Cr ratio showed } \\
\text { significant difference between patients with } \\
\text { GOS }=1-2(1.68 \pm 0.4 \text { NAA/Cr ratio }) \text { and } \\
\text { GOS }=4-5(2.1 \pm 0.3 \mathrm{NAA} / \mathrm{Cr} \text { ratio })\end{array}$ \\
\hline Marino et al. (2007) & 10 & $\begin{array}{l}\text { TBI; GCS } 4-7 \\
(n=7), \text { GCS } 8-13 \\
(n=3)\end{array}$ & TBI & $48-72 \mathrm{~h}$ & $\begin{array}{l}\text { Central brain: correlation of GOS with } \\
\text { NAA }(r=-0.79) \text { and La ratio }(r=0.79)\end{array}$ \\
\hline
\end{tabular}


Table 1. (Continued)

\begin{tabular}{|c|c|c|c|c|c|}
\hline Authors & $\begin{array}{l}\text { Number of } \\
\text { patients }\end{array}$ & Diagnosis & Etiology & Interval & Main findings \\
\hline Tollard et al. (2009) & 43 & $\begin{array}{l}\text { Closed-head injury, } \\
\text { GCS } \leq 7 \quad(n=43)\end{array}$ & TBI & $24 \pm 11 \mathrm{~d}$ & $\begin{array}{l}\text { Thalamus, lenticular nucleus, insular } \\
\text { cortical gray matter, occipital white matter: } \\
\text { NAA/Cr values at all sites lowest in } \\
\text { patients with GOS }=1-3(1.3 \pm 0.3 \text { NAA/ } \\
\text { Cr ratio }) \text { than with GOS }=4-5(1.7 \pm 0.4 \\
\text { NAA/Cr ratio) }\end{array}$ \\
\hline \multicolumn{6}{|l|}{ Diffusion weighted imaging } \\
\hline Schaefer (2004) & 26 & $\begin{array}{l}\text { Closed head injury; } \\
\text { GCS } 10 \pm 3(n=26)\end{array}$ & TBI & $<48 \mathrm{~h}$ & $\begin{array}{l}\text { Correlation between number of lesions and } \\
\text { outcome }(r=0.662) \text {; corpus callosum and } \\
\text { outcome }(r=0.513) \text {; brainstem lesion and } \\
\text { outcome ( } r=0.316) \text {; basal ganglia/ } \\
\text { thalamus and outcome }(r=0.179)\end{array}$ \\
\hline \multicolumn{6}{|l|}{ Diffusion tensor imaging } \\
\hline Huisman et al. (2004) & 20 & $\begin{array}{l}\text { Head traumatic } \\
\text { injury; GCS } 9 \pm 4 \\
(n=20)\end{array}$ & TBI & $<7 d$ & $\begin{array}{l}\text { Splenium: correlation between outcome } \\
\text { and ADC }(r=-0.599) \text {, and outcome and } \\
\text { FA }(r=-0.694) \text {; internal capsule: } \\
\text { correlation between outcome and FA } \\
(r=-0.714) \text {, no correlation between } \\
\text { outcome and ADC }(r=-0.018) \text {; thalamus/ } \\
\text { putamen: no correlation between outcome } \\
\text { and FA and ADC }\end{array}$ \\
\hline Tollard et al. (2009 & 43 & $\begin{array}{l}\text { Closed head injury; } \\
\text { GCS } \leq 7(n=43)\end{array}$ & TBI & $24 \pm 11 \mathrm{~d}$ & $\begin{array}{l}\text { Pons, midbrain, temporal and occipital } \\
\text { white matter, internal and external } \\
\text { capsules, semioval center: FA significantly } \\
\text { lower in patients with GOS } 1-3 \text { than with } \\
\text { GOS } 4-5 \text { patients, except in the posterior } \\
\text { pons; } 86 \% \text { sensitivity and } 97 \% \text { specificity } \\
\text { for predicting outcome by combining MRS } \\
\text { and DTI analysis }\end{array}$ \\
\hline Perlbarg et al. (2009) & 30 & $\begin{array}{l}\text { TBI with persistent } \\
\text { disorder of } \\
\text { consciousness; GCS } \\
6 \pm 4(n=30)\end{array}$ & TBI & $24 \pm 11 \mathrm{~d}$ & $\begin{array}{l}\text { FA significantly lower in GOS } 1-3 \text { than in } \\
\text { GOS } 4-5 \text { and controls in right inferior } \\
\text { longitudinal fasciculus, right cerebral } \\
\text { peduncle, right posterior limb of the } \\
\text { internal capsule and posterior corpus } \\
\text { callosum }\end{array}$ \\
\hline
\end{tabular}

Notes: GCS, Glasgow Coma Scale; TBI, traumatic brain injury; NA, not available; d, days; h, hours; DAI, diffuse axonal injury; NAA, $\mathrm{N}$-acetylaspartate; Cr, creatinine; Cho, choline; Ins, myo-inositol; GOS, Glasgow Outcome Scale; La, lactate; ADC, apparent diffusion coefficient; FA, fractional anisotropy.

or assessment of severity and extension of diffuse axonal injury (DAI). DAI consists in diffuse white matter damage, usually caused by the effect of brutal acceleration-deceleration and/or rotational forces; resulting in stretching, disruption, and separation of axons as the brain moves inside the skull and causing important morbidity and mortality (Adams et al., 1982; Strich, 1961; Gean, 1994; Murray et al., 1996). Morphological MRI assessments were however shown to be more sensitive and specific to assess the recovery of consciousness than computed tomodensitometry and electrophysiological tools (Wedekind et al., 1999).

Taking into account these considerations, conventional MRI cannot be considered as a reliable technique to assess brain-injured patients and predict their functional outcome. The lack of sensitivity of conventional MRI led to introduce new tools in the clinical assessment of comatose 


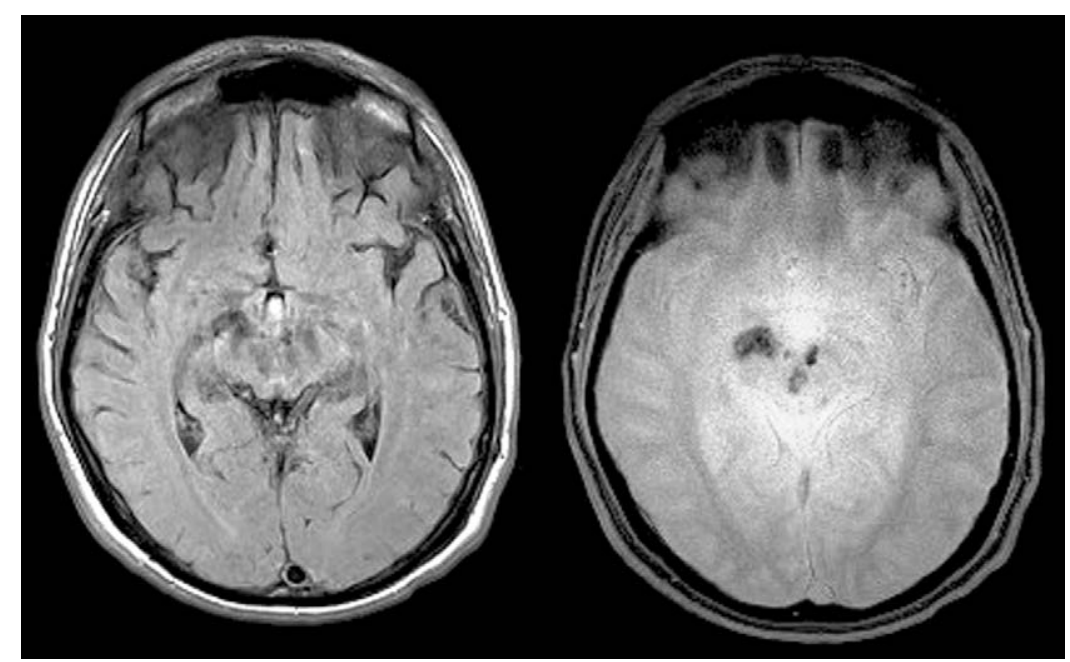

Fig. 1. Axial fluid attenuated inversion recovery (FLAIR) (left) and T2* (right) in a TBI minimally conscious patient. T2* sequence shows hyposignal in the midbrain suggestive of bleeding not clearly seen on FLAIR sequence.

patients such as positron emission tomography (PET; Beuthien-Baumann et al., 2003; Boly et al., 2008a; Laureys et al., 1999), functional MRI (fMRI; Boly et al., 2008b, Monti et al., 2009; Coleman et al., 2007; Owen et al., 2006), MRS (Cox, 1996), and DTI (Assaf and Pasternak, 2008; Voss et al. 2006). Preliminary studies suggest that these alternative functional and metabolic imaging methods could be more sensitive to detect brain damage immediately following TBI, and could thus be useful to monitoring longitudinal changes in brain function of non-communicative brain-damaged patients. In the future, they could play a crucial role in coma assessment, adding to a purely morphology-based imaging approach a more comprehensive evaluation of the patient's brain ability to generate consciousness, combining information on structure and function.

\section{Conventional MRI protocol}

In our view, in order to perform a comprehensive assessment of structural damage in individual coma patients, the morphologic MRI acquisitions should include noncontrast-enhanced sagittal T1, axial fluid attenuated inversion recovery (FLAIR), axial T2*, axial diffusion, coronal T2 sequences, and a 3D T1 weighted volume acquisition. In our centers, images are typically obtained with a section thickness of $5 \mathrm{~mm}$ (except for the 3D $\mathrm{T} 1$ which is millimetric). FLAIR sequence detects brain edema and contusion, epidural or subdural hematoma, subarachnoid hemorrhage, as well as the resulting herniation or hydrocephalus; while gradient echo-planar T2* weighted images are useful in detecting hemorrhage (Gerber et al., 2004; Scheid et al., 2003) (Fig. 1). The 3D T1 sequence provides information on the volume of the brain, and can be use during the follow up of patients. Indeed, severe and irreversible brain damage would lead to progressive brain atrophy, over a period of weeks to years (Trivedi et al., 2007).

\section{Diffusion tensor imaging protocol}

DTI is one of the most popular MRI techniques investigated in current brain-imaging research (Fig. 2). It is an extension of diffusion-weighted imaging (DWI) which is based on the principle that water molecule movement is restricted by barriers to diffusion in the brain depending on tissue organization. The acquisition protocol, image processing, analysis, and interpretation of DTI are now routinely performed in clinical conditions although it suffers from inherent 


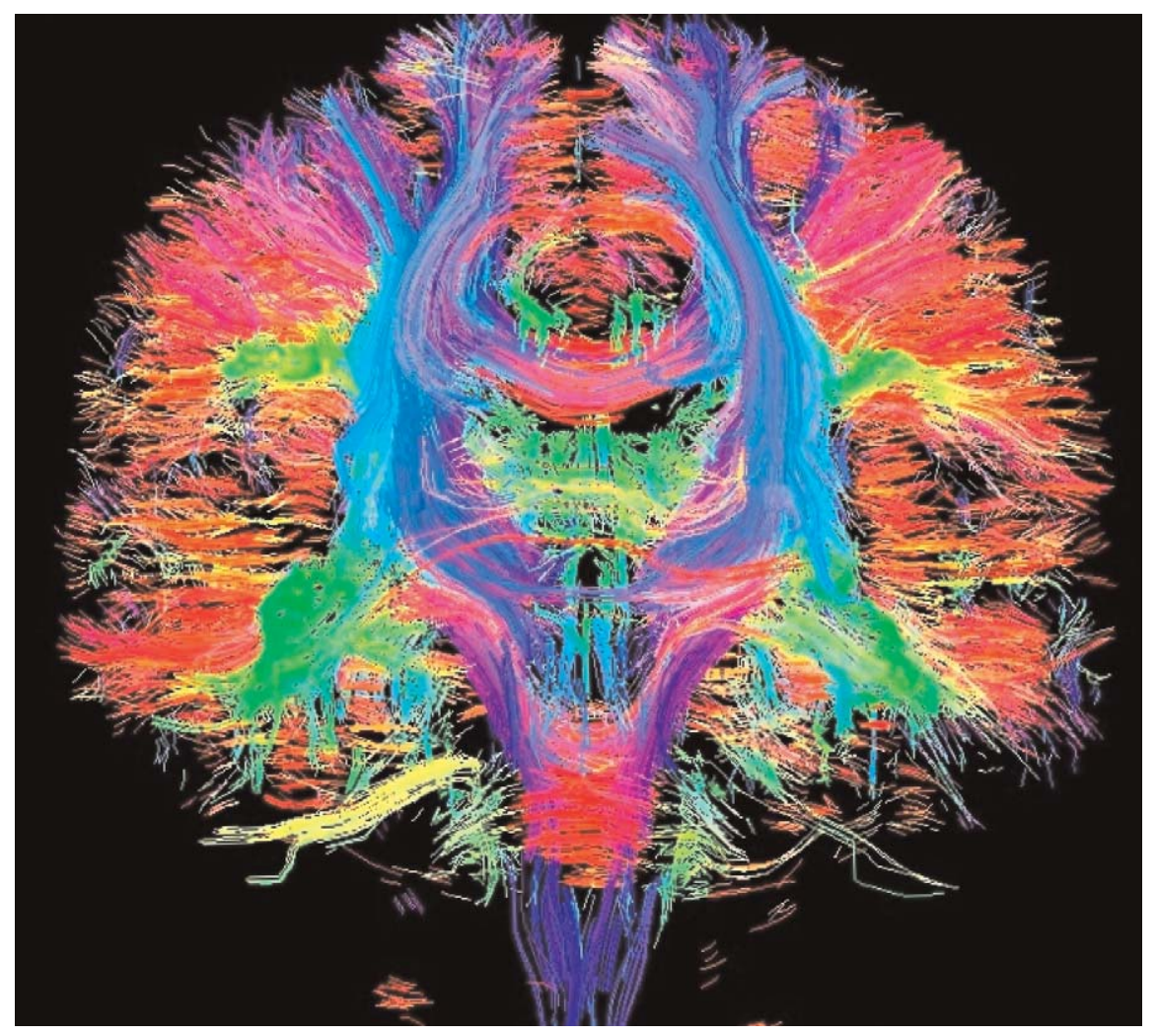

Fig. 2. Example of diffusion tensor imaging (DTI) obtained in a healthy volunteer, visualising the white matter tracts. Acquisition time: 4:51; TR/TE: $5700 / 90 \mathrm{~ms}$; Resolution: $128 \times 128$; Slices: 40 transversal slices $(2.0 \mathrm{~mm}$ thickness, $30 \%$ gap, interleaved); Voxel size: $1.8 \times 1.8 \times 2.0 \mathrm{~mm}^{3} ; \mathrm{FoV}: 230 \times 230 \mathrm{~mm}^{2}$.

artifacts and limitations such as the partial volume effect and the inability of the model to cope with non-Gaussian diffusion. DTI imaging is classically performed in axial plane, using the following parameters: TR/TE, 8000/84.9 ms; 23 directions; diffusion $b$ value, $700 \mathrm{~s} / \mathrm{mm}^{2}$; slice thickness, $5 \mathrm{~mm}$; no gap; 20 slices; field of view, $32 \times 32 \mathrm{~cm}$; matrix, $128 \times 128$; and 2 averages (Tollard et al., 2009). DTI provides data that can be used to compute two basic properties: the overall amount of diffusion represented by the apparent diffusion coefficient (ADC) and the fractional anisotropy (FA) which enable visualization and characterization of white matter (WM) in two and three dimensions. The FA characterizes the anisotropic component, that is, degree and directionality of water diffusion. Determination of FA allows a quantification of WM density in vivo and gives information about its integrity (Liu et al., 1999; Melhem et al., 2000; Pierpaoli et al., 1996). In our protocol of data acquisition and analysis, symmetric rectangular regions of interest (ROI) are also used for the quantitative measures positioning at several sites including the anterior and posterior pons, right and left midbrain, the right and left WM of temporal lobe, occipital lobe, posterior limb of the internal capsule, external capsule, anterior and posterior semiovale centrum (Tollard et al., 2009).

DWI and DTI show anomalies invisible on current morphological MRI even on $\mathrm{T} 2$ * sequence (Huisman et al., 2003) and can better assess the degree of neurological impairment than any other conventional MRI sequence (Shanmuganathan et al., 2004). DTI permits to identify specific fiber bundles such as the corpus 
callosum and the long association fibers that include cingulum, superior and inferior longitudinal fascicules, uncinate fasciculus, superior and inferior fronto-occipital fascicules. Other fibers bundles can also be visualized: brainstem tracts, projection fibers such as corticospinal and corticothalamic fibers. DTI is an appropriate technique to assess microstructural WM damage that occurs in TBI, particularly since the pathophysiological mechanisms altering water diffusion anisotropy include DAI and intracranial hypertension. Several studies confirmed that DWI is a valuable technique to assess DAI (Arfanakis et al., 2002; Huisman et al., 2003; Liu et al., 1999) and showed that DTI is sensitive to damage in tissue that may appear normal on conventional MRI sequences (Arfanakis et al., 2002; Chan et al., 2003). Over conventional sequences commonly used to assess DAI (such as FLAIR, T2*, diffusion-weighted, and susceptibility weighted), DTI offers the advantages of a greater sensitivity and the availability of quantitative information.

\section{Magnetic resonance spectroscopy protocol}

MRS provides in vivo biochemical information. The metabolites that can be identified with proton MRS are dependent on the echo time (TE). At $1.5 \mathrm{~T}$ and $3 \mathrm{~T}$, metabolites visualized utilizing intermediate-to-long TE (135-288 ms) include choline (Cho), creatine (Cr), N-acetylaspartate (NAA), and lactate (La). NAA is produced in the mitochondria of the neurons and transported into the neuronal cytoplasm and the axons. It is found in both gray and white matter in approximately equal quantities (Danielsen and Ross, 1999). In healthy subjects, there is an increase in NAA in gray matter from ventral to dorsal, and from the cerebral hemispheres to the spinal cord (Pouwels and Frahm, 1998). Several studies suggest NAA to be a brain osmolyte with possible reversible changes (Baslow et al., 2003, 2007; Moffett et al., 2007). It is considered as a marker of neuronal density and viability and functional status (Ebisu et al., 1994; Sullivan et al., 2001); its peak decrease when there is neuron suffering or loss. Choline is a metabolic marker of membrane synthesis and catabolism. MRS permits to detect free choline and phosphocholine, that is, those that are not incorporated into the macromolecules on the membrane surface (Ross and Michaelis, 1994). Its concentration is slightly greater in white than in gray matter. Its peak increases when there is greater membrane turnover, cell proliferation, or inflammatory process. Creatine is considered as a marker of the aerobic energy metabolism. It is assumed to be stable, hence is used for calculating metabolite ratios (NAA/Cr and $\mathrm{Cho} / \mathrm{Cr}$ ratios). Lactate is at the limit of detectability in normal human brain using the routine spectroscopic techniques. However, under anaerobic glycolysis conditions, such as brain hypoxia, ischemia, or severe posttraumatic injury, lactate level may increase significantly.

In our view, a comprehensive MRS protocol to assess brain function in comatose patients should include single-voxel ${ }^{1} \mathrm{H}$ spectroscopy (SVS) placed on the posterior two-thirds of the pons (the parameters we typically use are: TR/TE, 1500/135 ms; matrix, $1 \times 1$; voxel thickness, $20 \mathrm{~mm}$; and 96 averages) (Fig. 3) and an axial chemical shift imaging (CSI) at the level of the basal ganglia to include thalamus, insular cortex, and periventricular $\mathrm{WM}$ in the field of exploration (the parameters we typically use are: TR/TE, $1500 / 135 \mathrm{~ms}$; field of view, $24 \times 24 \mathrm{~cm}$; matrix, $18 \times 18$; slice thickness, $15 \mathrm{~mm}$; and NEX, 1) (Tollard et al., 2009) (Fig. 4). In our clinical practice, the SVS is usually performed in the pons for three reasons. First, the pons contains a large part of the ascending reticular activating system; second, the pons is often affected by DAIs not necessarily seen on FLAIR and T2* sequences; and third, the pons can be damaged from both primary and secondary cerebral injuries due to temporal lobe herniation (Carpentier et al., 2006). Patients with bilateral lesions of the protuberance on standard morphological MRI sequences have been reported with a 100\% mortality rate (Firsching et al., 1998). Finally, MRS has a better sensitivity than $\mathrm{T} 2$ * sequence in the detection of ischemic or hemorrhagic diffuse axonal lesions in TBI (Cecil et al., 1998). 


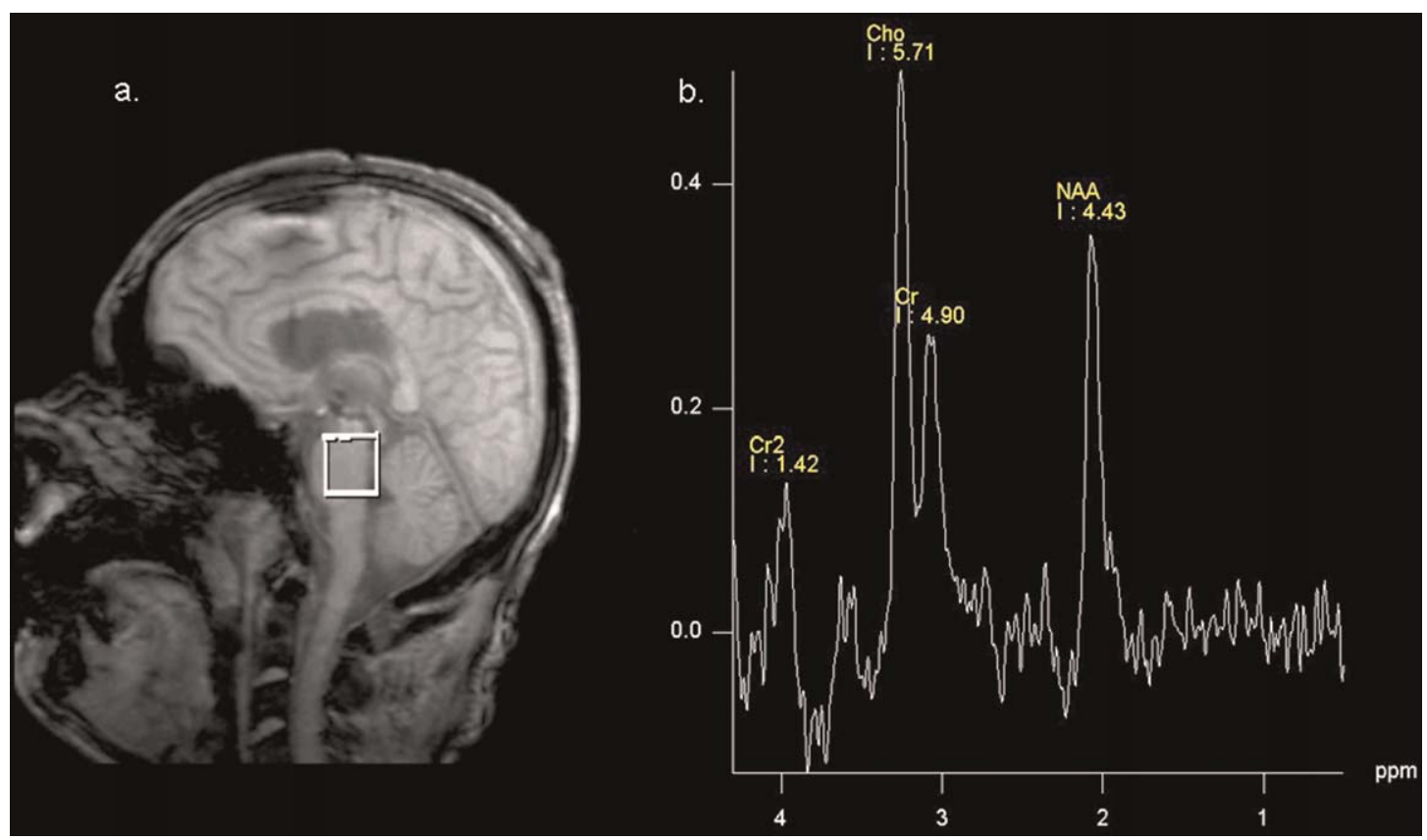

Fig. 3. Monovoxel spectroscopic (SVS) of the pons in a TBI patient. a: Location of the voxel on the sagittal T1-weighted acquisition. b: Decreased NAA spectrum (NAA/Cr $=0.90$ and $\mathrm{NAA} / \mathrm{Cho}+\mathrm{Cr}+\mathrm{NAA}=0.29)$.

\section{Comatose patients assessment}

The timing of an optimal MRI assessment in comatose patients remains controversial (Table 1). An acute exploration may take into account reversible lesions such as edema or miss secondary lesions due to intracranial hypertension or systemic disorders. On the contrary, an examination performed late after the injury may only detect sequels such as global aspecific atrophy and has no impact on the initial medical management and on altered state of consciousness status prediction. With regard to time since TBI or stroke, MRS and DTI findings vary greatly and studies are heterogeneous as illustrated by last studies performed with MRS sequences. Four phases may be distinguished: an acute phase, which lasts $24 \mathrm{~h}$ after TBI; an early subacute phase, from the day 1 to 13; a late subacute phase, from days 14 to 20; and a chronic phase, which starts on day 21 (Weiss et al., 2007). Among these MRS studies, two included patients at the acute phase (Marino et al.,
2007; Ross et al., 1998), two from the early subacute phase to the first month (Carpentier et al., 2006; Garnett et al., 2000), one at the late subacute phase up to 11 months (Choe et al., 1995), and four at the chronic phase from 3 weeks to 8 months after TBI (Friedman et al., 1999; Ricci et al., 1997; Sinson et al., 2001; Uzan et al., 2003). In a retrospective study using DTI, comatose patients were excluded if the time delay between trauma and MRI exceeded 7 days to avoid the various changes in anisotropic diffusion related to secondary tissue injury (Huisman et al., 2004). An early examination with precise quantification of the extent and degree of brain injury is essential for treatment decisions (i.e., to determine outcome, cognitive and behavioral deficits), and becomes a criterion of good practice in management of these patients. The late subacute phase seems to be the best moment to assess comatose patients taking into account the physiopathology and all issues (medical, ethical, legal, social) raised by the management of these patients. 


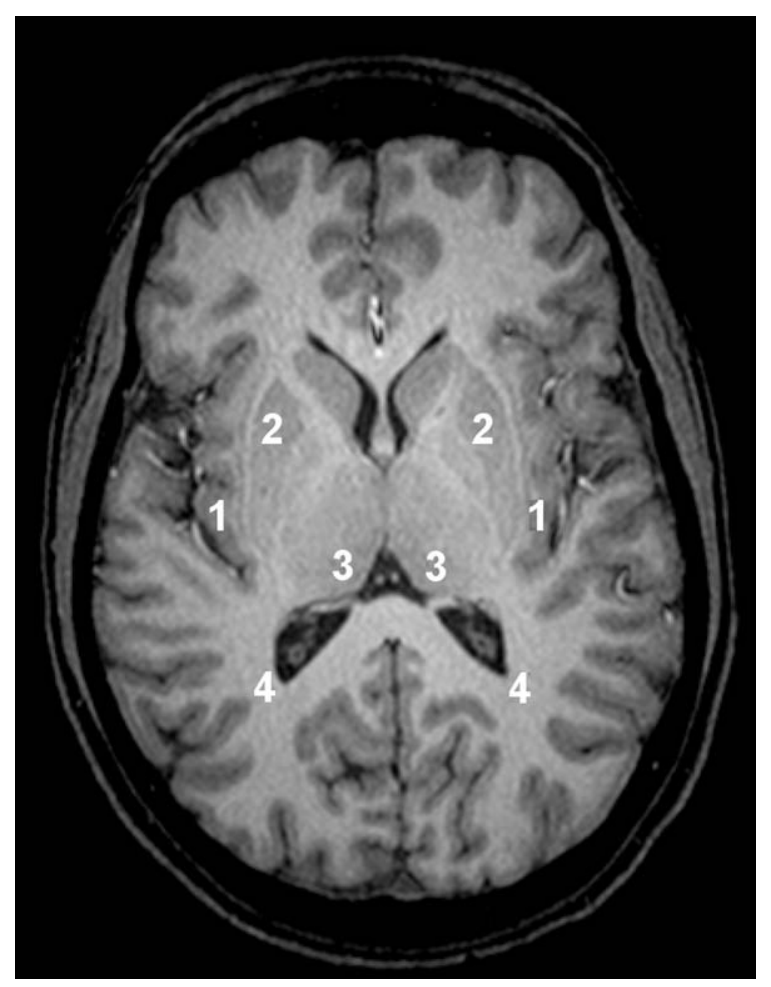

Fig. 4. Chemical shift imaging (CSI). Position of regions of interest: insula (1), lenticular nucleus (2), thalamus (3), and periventricular white matter (4).

\section{Prediction of outcome with MRI}

Although clinical examination and conventional imaging techniques provide useful information for TBI patient screening and acute care, none of them accurately predicts individual patient outcome. Developing a reliable MRI outcomeprediction tool is a major challenge for all physicians in charge of comatose patients. It would provide an objective basis for deciding to go on with prolonged aggressive care or to remove life-supporting therapy as well as for informing families and planning rehabilitation.

\section{Conventional MRI}

There is some evidence that MRI may have potential in terms of predicting outcome according to several studies performed with conventional MRI. Firsching and colleagues (1998) performed a prospective MRI study in 61 consecutive patients within 7 days after their injury. They found bilateral pontine lesions to be $100 \%$ fatal, whereas unilateral brainstem lesions were responsible of similar mortality rate as in patients with no brainstem injury and conclude that early MRI after head injury had a higher predictive value than CT scanning. Other studies have showed that MRI scans performed at acute and subacute phase after head injury provide several indicators for unfavorable outcome when there are lesions within the corpus callosum and dorsolateral brainstem (Kampfl et al.,1998), basal ganglia, hippocampus, midbrain, and pons (Wedekind et al., 1999). Presence of hemorrhage in DAI-type lesions and the association with traumatic space-occupying lesions was indicative of poor prognostic sign. Isolated non-hemorrhagic DAI-type lesions were not associated with poor clinical outcome (Paterakis et al., 2000). Hoelper 
et al. (2000) observed that the number $(>3)$ and volume $(>1.5 \mathrm{~mL})$ of brainstem lesions correlated with unfavorable outcome. There are also some evidences that the total lesion volume on FLAIR images correlates significantly with clinical outcome. The volume of lesions of the corpus callosum on the FLAIR sequence correlated significantly with scores on disability and cognition scales at the first clinical assessment. Volume of FLAIR lesions in the frontal lobes correlated significantly with outcome after 1 year (Pierallini et al., 2000). Moreover, the number of lesions detected by $\mathrm{T} 2 *$ was also shown as significantly greater than that detected by T2-FSE (Yanagawa et al., 2000). Lesions detected by T2* and FLAIR were inversely correlated with outcome of patient (Yanagawa et al., 2000; Carpentier et al., 2006).

In spite of these multiple morphological MRI studies and their encouraging results (Table 1), it remains difficult to explain why some patients in persistent vegetative state or with long-term marked cognitive impairments have no or minimal lesions on conventional MR examination performed with $\mathrm{T} 2 *$ and diffusion sequences. Therefore, morphological MRI alone cannot be considered as a reliable tool to assess coma severity, and to predict the comatose patient functional outcome.

\section{Magnetic resonance spectroscopy}

To our knowledge, Choe et al. (1995) performed the first assessment of patient with closed head injury using in vivo proton MRS to evaluate neuronal and axonal dysfunction. The main result in this case-control study was a significant decrease of NAA/Cr ratio compared with normal controls. The level of NAA/Cr ratio was significantly correlated with Glasgow Outcome Scale (GOS; Jennett and Bond, 1975) whereas no clear correlation of other metabolite ratios such as Cho/Cr was observed. Since then, several investigations that do appear in the literature were promising in terms of the role of proton MRS as an accurate tool to predict patient outcome. Ricci et al. (1997) examined 14 vegetative brain-injured patients with proton magnetic resonance singlevolume spectroscopy performed 1-90 months after the injury. Cho/Cr was significantly higher, whereas NAA/Cho and NAA/Cr were markedly lower than in the control subjects. The NAA/Cho ratio was statistically significant in discriminating between the patients with a poor outcome (GOS score, 1-2) and those who regained awareness. Other studies have showed a reduced NAA/Cr level in gray and white matter of occipito-parietal regions in acute and subacute phase after injury, which correlated with bad outcome (Ross et al., 1998; Friedman et al., 1999). The frontal WM $\mathrm{NAA} / \mathrm{Cr}$ acquired in the subacute phase significantly correlated with patient outcome, whereas Cho/Cr was increased at both the early and late phase compared with controls (Garnett et al., 2000). Decreased NAA/Cr ratio in the splenium of corpus callosum also correlated with the GOS score of acute and chronic patients (Sinson et al., 2001). The NAA/Cr ratio was reduced in the thalami of both persistent vegetative patients and patients who recovered 6-8 months after injury (Uzan et al., 2003). Moreover, NAA/Cr ratios were lower in persistent vegetative patient than in patients who regained awareness. Carpentier et al. (2006) observed three MRS profile of the pons after TBI: normal profile (the peak of NAA is higher than the peaks of Cho and $\mathrm{Cr}$ ), neuronal loss profile (the NAA peak is decreased, nearly to the level of the $\mathrm{Cr}$ peak; the $\mathrm{NAA} / \mathrm{Cr}$ ratio is $<1.50$ and NAA/Cho+Cr+NAA $<0.40$ ) (Fig. 3), and gliosis profile (increased Cho peak with no change in the $\mathrm{Cr}$ or NAA peak and $\mathrm{Cho} /$ $\mathrm{Cr}>\mathrm{NAA} / \mathrm{Cr}$ or $\mathrm{Cho} / \mathrm{Cho}+\mathrm{Cr}+\mathrm{NAA}>0.40$ ).

The NAA/Cr ratio was correlated with the GOS score but not with lesions burden on $\mathrm{T} 2 *$ or FLAIR, whereas this lesions burden was correlated with the outcome score. Therefore, MRS and conventional MR seem to be complementary. The combination of these two techniques may be useful. Other people showed that NAA/Cr and NAA/all metabolites ratios to be significantly lower in the medial cortex of patients with TBI than in normal controls, whereas the $\mathrm{La} / \mathrm{Cr}$ and $\mathrm{La}$ /all metabolites ratios were increased (Marino et al., 2007). Both NAA and La ratios correlated with GOS score. Data of MRS performed early after brain injury are clinically relevant. Increased La detected may be, at this stage, a reliable index 
of injury severity and disease outcome in patients with TBI. Cohen et al. (2007) included 20 patients in a case-control study with the purpose to quantify the global decline of the neuronal marker NAA, as well as gray and white matter atrophy after mild traumatic brain injury (mTBI). Patients with mTBI exhibited, on average, a $12 \%$ wholebrain NAA deficit, which increased with age, as compared with the control subjects. Volumetric MRI in their patients showed decreased volume of gray matter, which, in combination with low whole-brain NAA, strongly suggests damage to the neurons and their axons. Tollard et al. (2009) observed NAA/Cr values at all measurement sites to be lowest in group of patients with unfavorable outcome (GOS, 1-3), intermediate in patients with favorable outcome (GOS, 4-5), and highest in control group. They did not find correlations between metabolic ratios and FA values; in particular, the NAA/Cr ratio of the pons was not correlated with the infratentorial FA value. Interestingly an unfavorable outcome after 1 year was predicted with up to $86 \%$ sensitivity and $97 \%$ specificity when taking into account both DTI and MRS values. Sensitivity was $79 \%$ and specificity $85 \%$ with FA only; corresponding values with MRS only were $75 \%$ and $75 \%$.

In conclusion, proton MRS should be added to morphological MR examinations with minimal additional time. It is proved to be useful in assessing injury severity, guiding patient care, and predicting patient outcome (Table 1). We agree with Weiss et al. (2007) that MRS studies in TBI patients are heterogeneous in terms of patient selection, time from TBI to MRS, voxel location, method of outcome assessment, and timing of outcome assessment. MRS research suffers from disparate acquisition protocols across research teams. However, the normal NAA/Cr ratio in identical regions is similar across studies and its decrease appears to be a reliable index of unfavorable outcome. The NAA is shown to decrease within a few minutes after TBI and reach the trough value within $48 \mathrm{~h}$. Its level remains stable within the first month after TBI, supporting the validity of MRS assessment during the second or third week (Holshouser et al., 2006; Signoretti et al., 2002). The later evolution of the NAA/Cr ratio between 6 weeks and 1 year after TBI is more heterogeneous, and NAA levels have been shown to decrease or increase. This possible variability in NAA levels is a potential limitation of this technique. In addition, the use of ratios may be problematic in TBI. Cr is assumed to be stable in normal brain tissue and used to standardize other brain metabolites. However, to the best of our knowledge, there is no evidence that $\mathrm{Cr}$ is invariable in TBI. Indeed, it could be affected similarly to the metabolite of interest as well (it is suggested to be reduced in hypermetabolic and raised in hypometabolic states; Castillo et al., 1996; Wood et al., 2003). This issue is important in particular as metabolism may be compromised in mTBI (Lewine et al., 1999). To minimize the potential negative impact of the NAA variability, repeated MRS examination during the subacute phase is probably needed and the whole-brain NAA estimation would improve the MRS yield. Studies have to be performed to prove the stability of $\mathrm{Cr}$ in TBI.

\section{Diffusion tensor imaging}

DTI may be a valuable biomarker for the severity of tissue injury and a predictor for outcome. It reveals changes in the WM that are correlated with both acute GCS and Rankin scores at discharge (Huisman et al., 2004). Significant early reduction of anisotropy was observed in WM structures, in particular in the internal capsule and the corpus callosum, which are the sites most commonly involved by DAI (Arfanakis et al., 2002). Moreover, several regions recovered normal values of anisotropy 1 month after the injury (Arfanakis et al., 2002). Xu et al. (2007) found significant differences in the corpus callosum, internal and external capsule, superior and inferior longitudinal fascicles, and the fornix in TBI patients. They showed that FA and ADC measurements offered superior sensitivity compared to conventional MRI diagnosis of DAI. Salmond et al. (2006) reported increased diffusivity in TBI patients at least 6 months after their injury in the cerebellum, frontal, insula, cingulate, parietal, temporal, and occipital lobes. 
The anisotropy seems to be reduced both in the major WM tracts such as the corpus callosum and the internal and external capsule, and the associative fibers underlying the cortex. DTI has a number of advantages as an imaging biomarker of brain injury: first, it can be used to evaluate brain trauma in an unconscious or sedated patient; second, it could permit the evaluation of responses to treatment even when the clinical scores are inadequate for assessing the patient; third, quantitative DTI measurements are unlikely to be tainted by adverse central nervous system (CNS) effects of hypnotic drugs, unlike clinical scores; and fourth, DTI may be an important alternative marker, as low initial GCS scores are of limited value in predicting the prognosis (Huisman et al., 2004). Finally, Perlbarg et al. (2009) showed significant FA differences between favorable and unfavorable 1-year outcome groups around four FA tracks: in inferior longitudinal fasciculus, posterior limb of the internal capsule, cerebral peduncle, and posterior corpus callosum.

\section{Conclusion}

In the future, DTI and MRS may permit to evaluate response to therapeutic interventions in TBI even when the clinical scores are inadequate for assessing the patient. MRS and DTI detect abnormalities not demonstrated on conventional MRI or CT structural scans, which are generally correlated with clinical outcomes. It is becoming increasingly obvious that these techniques are complementary and that both could be required to explore comatose patients at subacute stage from TBI as part of a comprehensive multimodal MRI and clinical assessment. Their combination will also possibly allow the pathogenesis of brain impairment to be better understood and the outcome better predicted. However, it is important to keep in mind some pitfalls such as the variability of NAA values and the impact of brain swelling which can, respectively, diminish the reliability of NAA and early FA measurement for predicting outcome in individual braindamaged patients.

\section{Acknowledgments}

This research was supported by the Fonds de la Recherche Scientifique (FRS), European Commission (DISCOS, Mindbridge \& COST BM0605), McDonnell Foundation, Mind Science Foundation, Reine Elisabeth Medical Foundation, the French Speaking Community Concerted Research Action (ARC-06/11-340) and University and University Hospital of Liège. A. Vanhaudenhuyse was funded by ARC 06/11-340; M. Boly, and S. Laureys are, respectively, Research Fellow, Postdoctoral Researcher, and Senior Research Associate at FRS. The authors thank the technicians of the Department of Neuro-Radiology and the nurses of the Intensive Care Units of the PitiéSalpêtrière Hospital, Paris and Centre Hospitalier Universitaire, Liège, for their active participation in the MRI studies in comatose patients.

\section{References}

Adams, J. H., Graham, D. I., Murray, L. S., \& Scott, G. (1982). Diffuse axonal injury due to nonmissile head injury in humans: An analysis of 45 cases. Annals of Neurology, 12, 557-563.

Anderson, C. V., Wood, D. M., Bigler, E. D., \& Blatter, D. D. (1996). Lesion volume, injury severity, and thalamic integrity following head injury. Journal of Neurotrauma, 13, 59-65.

Andrews, K., Murphy, L., Munday, R., \& Littlewood, C. (1996). Misdiagnosis of the vegetative state: Retrospective study in a rehabilitation unit. British Medical Journal, 313(7048), 13-16.

Arfanakis, K., Haughton, V. M., Carew, J. D., Rogers, B. P., Dempsey, R. J., \& Meyerand, M. E. (2002). Diffusion tensor MR imaging in diffuse axonal injury. American Journal of Neuroradiology, 23, 794-802.

Assaf, Y., \& Pasternak, O. (2008). Diffusion tensor imaging (DTI)-based white matter mapping in brain research: A review. Journal of Molecule Neuroscience, 34, 51-61.

Baslow, M. H., Hrabe, J., \& Guilfoyle, D. N. (2007). Dynamic relationship between neurostimulation and $\mathrm{N}$ acetylaspartate metabolism in the human visual cortex: Evidence that NAA functions as a molecular water pump during visual stimulation. Journal of Molecule Neuroscience, 32, 235-245.

Baslow, M. H., Suckow, R. F., Gaynor, K., Bhakoo, K. K., Marks, N., Saito, M., et al. (2003). Brain damage results in down-regulation of $\mathrm{N}$-acetylaspartate as a neuronal osmolyte. Neuromolecular Medicine, 3, 95-104. 
Beuthien-Baumann, B., Handrick, W., Schmidt, T., Burchert, W., Oehme, L., Kropp, J., et al. (2003). Persistent vegetative state: Evaluation of brain metabolism and brain perfusion with PET and SPECT. Nuclear Medicine Communications, 24, 643-649.

Boly, M., Faymonville, M. E., Schnakers, C., Peigneux, P., Lambermont, B., Phillips, C., et al. (2008a). Perception of pain in the minimally conscious state with PET activation: An observational study. Lancet Neurology, 7(11), 1013-1020.

Boly, M., Phillips, C., Tshibanda, L., Vanhaudenhuyse, A., Schabus, M., Dang-Vu, T. T., et al. (2008b). Intrinsic brain activity in altered states of consciousness. How conscious is the default mode of brain function? Annals of the New York Academy of Sciences, 1129, 119-129.

Carpentier, A., Galanaud, D., Puybasset, L., Muller, J. C., Lescot, T., Boch, A. L., et al. (2006). Early morphologic and spectroscopic magnetic resonance in severe traumatic brain injuries can detect "invisible brain stem damage" and predict "vegetative states". Journal of Neurotrauma, 23, 674-685.

Castillo, M., Kwock, L., \& Mukherji, S. K. (1996). Clinical applications of proton MR spectroscopy. American Journal of Neuroradiology, 17, 1-15.

Cecil, K. M., Hills, E. C., Sandel, M. E., Smith, D. H., McIntosh, T. K., Mannon, L. J., et al. (1998). Proton magnetic resonance spectroscopy for detection of axonal injury in the splenium of the corpus callosum of braininjured patients. Journal of Neurosurgery, 88, 795-801.

Celesia, G. (1993). Persistent vegetative state. Neurology, 43, 1457-1458.

Chan, Y. L., Chu, W. C., Wong, G. W., \& Yeung, D. K. (2003). Diffusion-weighted MRI in shaken baby syndrome. Pediatric Radiology, 33, 574-577.

Childs, N. L., \& Mercer, W. N. (1996). Misdiagnosing the persistent vegetative state. Misdiagnosis certainly occurs. British Medical Journal, 313(7062), 944.

Choe, B. Y., Suh, T. S., Choi, K. H., Shinn, K. S., Park, C. K., \& Kang, J. K. (1995). Neuronal dysfunction in patients with closed head injury evaluated by in vivo $1 \mathrm{H}$ magnetic resonance spectroscopy. Investigative Radiology, 30, 502-506.

Cohen, B. A., Inglese, M., Rusinek, H., Babb, J. S., Grossman, R. I., \& Gonen, O. (2007). Proton MR spectroscopy and MRI-volumetry in mild traumatic brain injury. American Journal of Neuroradiology, 28, 907-913.

Coleman, M. R., Rodd, J. M., Davis, M. H., Johnsrude, I. S., Menon, D. K., Pickard, J. D., et al. (2007). Do vegetative patients retain aspects of language comprehension? Evidence from fMRI. Brain, 130, 2494-2507.

Cox, I. J. (1996). Development and applications of in vivo clinical magnetic resonance spectroscopy. Progress in Biophysics and Molecular Biology, 65, 45-81.

Danielsen, E. R., \& Ross, B. (1999). Magnetic resonance spectroscopy diagnosis of neurological diseases (1st ed.). New York: Marcel Dekker, Inc.

Ebisu, T., Rooney, W. D., Graham, S. H., Weiner, M. W., \& Maudsley, A. A. (1994). N-acetylaspartate as an in vivo marker of neuronal viability in kainate-induced status epilepticus: $1 \mathrm{H}$ magnetic resonance spectroscopic imaging. Journal of Cerebral Blood Flow \& Metabolism, 14, 373-382.

Firsching, R., Woischneck, D., Diedrich, M., Klein, S., Ruckert, A., Wittig, H., et al. (1998). Early magnetic resonance imaging of brainstem lesions after severe head injury. Journal of Neurosurgery, 89, 707-712.

Friedman, S., Brooks, W., Jung, R., Chiulli, S., Sloan, J., Montoya, B., et al. (1999). Quantitative proton MRS predicts outcome after traumatic brain injury. Neurology, 52, 1384-1391.

Gale, S. D., Johnson, S. C., Bigler, E. D., \& Blatter, D. D. (1995). Trauma-induced degenerative changes in brain injury: A morphometric analysis of three patients with preinjury and postinjury MR scans. Journal of Neurotrauma, $12,151-158$.

Garnett, M. R., Blamire, A. M., Corkill, R. G., CadouxHudson, T. A., Rajagopalan, B., \& Styles, P. (2000). Early proton magnetic resonance spectroscopy in normal-appearing brain correlates with outcome in patients following traumatic brain injury. Brain, 123, 2046-2054.

Gean, A. D. (1994). White matter shearing injury and brainstem injury. New York: Raven.

Gentry, L. R., Godersky, J. C., Thompson, B., \& Dunn, V. D. (1988). Prospective comparative study of intermediate-field MR and CT in the evaluation of closed head trauma. American Journal of Roentgenology, 150, 673-682.

Gerber, D. J., Weintraub, A. H., Cusick, C. P., Ricci, P., \& Whiteneck, G. G. (2004). Magnetic resonance imaging of traumatic brain injury: Relationship of $\mathrm{T} 2 * \mathrm{SE}$ and T2GE to clinical severity and outcome. Brain Injury, 18, 1083-1097.

Hoelper, B. M., Soldner, F., Chone, L., \& Wallenfang, T. (2000). Effect of intracerebral lesions detected in early MRI on outcome after acute brain injury. Acta Neurochirurgica. Supplement, 76, 265-267.

Holshouser, B. A., Tong, K. A., Ashwal, S., Oyoyo, U., Ghamsary, M., Saunders, D., et al. (2006). Prospective longitudinal proton magnetic resonance spectroscopic imaging in adult traumatic brain injury. Journal of Magnetic Resonance Imaging, 24, 33-40.

Huisman, T., Sorensen, A., Hergan, K., Gonzalez, R., \& Schaefer, P. (2003). Diffusion-weighted imaging for the evaluation of diffuse axonal injury in closed head injury. Journal of Computer Assisted Tomography, 27, 5-11.

Huisman, T. A., Schwamm, L. H., Schaefer, P. W., Koroshetz, W. J., Shetty-Alva, N., Ozsunar, Y., et al. (2004). Diffusion tensor imaging as potential biomarker of white matter injury in diffuse axonal injury. American Journal of Neuroradiology, 25, 370-376.

Jennett, B. (2005). 30 years of the vegetative state: Clinical, ethical and legal problems. In S. Laureys (Ed.), The boundaries of consciousness: Neurobiology and neuropathology (Vol. 150, pp. 541-548). Amsterdam: Elsevier.

Jennett, B., \& Bond, M. (1975). Assessment of outcome after severe brain damage. Lancet, 7905, 480-484.

Kampfl, A., Schmutzhard, E., Franz, G., Pfausler, B., Haring, H. P., Ulmer, H., et al. (1998). Prediction of recovery from 
post-traumatic vegetative state with cerebral magneticresonance imaging. Lancet, 351, 1763-1767.

Katz, D. (1997). Traumatic brain injury. Malden: Blackwell Science.

Kelly, A. B., Zimmerman, R. D., Snow, R. B., Gandy, S. E., Heier, L. A., \& Deck, M. D. F. (1988). Head trauma: Comparison of MR and CT-experience in 100 patients. American Journal of Neuroradiology, 9, 699-708.

Laureys, S., Goldman, S., Phillips, C., Van Bogaert, P., Aerts, J., Luxen, A., et al. (1999). Impaired effective cortical connectivity in vegetative state. Neuroimage, 9, 377-382.

Lewine, J. D., Davis, J. T., Sloan, J. H., Kodituwakku, P. W., \& Orrison, W. W., Jr. (1999). Neuromagnetic assessment of pathophysiologic brain activity induced by minor head trauma. American Journal of Neuroradiology, 20, 857-866.

Liu, A. Y., Maldjian, J. A., Bagley, L. J., Sinson, G. P., \& Grossman, R. I. (1999). Traumatic brain injury: Diffusionweighted MR imaging findings. American Journal of Neuroradiology, 20, 1636-1641.

Marino, S., Zei, E., Battaglini, M., Vittori, C., Buscalferri, A., Bramanti, P., et al. (2007). Acute metabolic brain changes following traumatic brain injury and their relevance to clinical severity and outcome. Jounral of Neurology, Neurosurgery and Psychiatry, 78, 501-507.

Melhem, E. R., Itoh, R., Jones, L., \& Barker, P. B. (2000). Diffusion tensor MR imaging of the brain: Effect of diffusion weighting on trace and anisotropy measurements. American Journal of Neuroradiology, 21, 1813-1820.

Moffett, J. R., Ross, B., Arun, P., Madhavarao, C. N., \& Namboodiri, A. M. (2007). N-Acetylaspartate in the CNS: From neurodiagnostics to neurobiology. Progress in Neurobiology, 81, 89-131.

Monti, M. M., Coleman, M. R., \& Owen, A. M. (2009). Neuroimaging and the vegetative state: Resolving the behavioral assessment dilemma? Annals of the New York Academy of Sciences, 1157(March), 81-89.

Murray, J. G., Gean, A. D., \& Evans, S. J. (1996). Imaging of acute head injury. Seminars in Ultrasound, CT and MRI, 17, 185-205.

Owen, A. M., Coleman, M. R., Boly, M., Davis, M. H., Laureys, S., \& Pickard, J. D. (2006). Detecting awareness in the vegetative state. Science, 13, 1402.

Parvizi, J., \& Damasio, A. (2001). Consciousness and the brainstem. Cognition, 79, 135-160.

Paterakis, K., Karantanas, A. H., Komnos, A., \& Volikas, Z. (2000). Outcome of patients with diffuse axonal injury: The significance and prognostic value of MRI in the acute phase. Journal of Trauma, 49, 1071-1075.

Payne, K., Taylor, R. M., Stocking, C., \& Sachs, G. A. (1996). Physicians' attitudes about the care of patients in the persistent vegetative state: A national survey. Annals of Internal Medicine, 125, 104-110.

Perlbarg, V., Puybasset, L., Tollard, E., Lehéricy, S., Benali, H., \& Galanaud, D. (2009). Relation between brain lesion location and clinical outcome in patients with severe traumatic brain injury: A diffusion tensor imaging study using voxel-based approaches. Human Brain Mapping (in press).

Pierallini, A., Pantano, P., Fantozzi, L. M., Bonamini, M., Vichi, R., Zylberman, R., et al. (2000). Correlation between MRI findings and long-term outcome in patients with severe brain trauma. Neuroradiology, 42, 860-867.

Pierpaoli, C., Jezzard, P., Basser, P. J., Barnett, A., \& Di Chiro, G. (1996). Diffusion tensor MR imaging of the human brain. Radiology, 201, 637-648.

Plum, F., \& Posner, J. (1980). The diagnosis of stupor and coma (3rd ed.). Oxford, UK: Oxford University Press.

Pouwels, P. J., \& Frahm, J. (1998). Regional metabolite concentrations in human brain as determined by quantitative localized proton MRS. Magnetic Resonance Medicine, 39, 53-60.

Ricci, R., Barbarella, G., Musi, P., Boldrini, P., Trevisan, C., \& Basaglia, N. (1997). Localised proton MR spectroscopy of brain metabolism changes in vegetative patients. Neuro radiology, 313-319.

Ross, B., \& Michaelis, T. (1994). Clinical applications of magnetic resonance spectroscopy. Magnetic Resonance Quarterly, 10, 191-247.

Ross, B. D., Ernst, T., Kreis, R., Haseler, L. J., Bayer, S., Danielsen, E., et al. (1998). 1H MRS in acute traumatic brain injury. Journal of Magnetic Resonance Imaging, 8, 829-840.

Salmond, C. H., Menon, D. K., Chatfield, D. A., Williams, G. B., Pena, A., Sahakian, B. J., et al. (2006). Diffusion tensor imaging in chronic head injury survivors: Correlations with learning and memory indices. Neuroimage, 29, 117-124.

Schaefer, P. W., Huisman, T. A. G., Sorensen, A. G., Gonzalez, R. G., \& Schwamm, L. H. (2004). Diffusionweighted MR imaging in closed head injury: High correlation with initial Glasgow Coma Scale score and score on Modified Ranking Scale at Discharge. Radiology, 233(1), 58-66.

Scheid, R., Preul, C., Gruber, O., Wiggins, C., \& von Cramon, D. Y. (2003). Diffuse axonal injury associated with chronic traumatic brain injury: Evidence from $\mathrm{T} 2 *$-weighted gradient-echo imaging at 3 T. American Journal of Neuroradiology, 24, 1049-1056.

Schnakers, C., Vanhaudenhuyse, A., Giacino, J., Ventura, M., Boly, M., Majerus, S., et al. (2009). Diagnostic accuracy of the vegetative and minimally conscious state: Clinical consensus versus standardized neurobehavioral assessment. BMC Neurology, 21(9), 35.

Selden, N., Gitelman, D., Salamon-Murayama, N., Parrish, T., \& Mesulam, M. (1998). Trajectories of cholinergic pathways within the cerebral hemispheres of the human brain. Brain, 121, 2249-2257.

Shanmuganathan, K., Gullapalli, R. P., Mirvis, S. E., Roys, S., \& Murthy, P. (2004). Whole-brain apparent diffusion coefficient in traumatic brain injury: Correlation with Glasgow Coma Scale. American Jounral of Neuroradiogy, $25,539-544$.

Signoretti, S., Marmarou, A., Fatouros, P., Hoyle, R., Beaumont, A., Sawauchi, S., et al. (2002). Application of chemical shift 
imaging for measurement of NAA in head injured patients. Acta Neurochirurgica. Supplement, 81, 373-375.

Sinson, G., Bagley, L. J., Cecil, K. M., Torchia, M., McGowan, J. C., Lenkinski, R. E., et al. (2001). Magnetization transfer imaging and proton MR spectroscopy in the evaluation of axonal injury: Correlation with clinical outcome after traumatic brain injury. American Journal Neuroradiology, 22, 143-151.

Strich, S. J. (1961). Shearing of nerve fibres as a cause of brain damage due to head injury: A pathological study of twenty cases. Lancet, 2, 443-448.

Sullivan, E. V., Adalsteinsson, E., Spielman, D. M., Hurd, R. E., \& Pfefferbaum, A. (2001). N-acetylaspartate - A marker of neuronal integrity. Annals of Neurology, 50, 824-825.

Tollard, E., Galanaud, D., Perlbarg, V., Sanchez-Pena, P., Le Fur, Y., Abdennour, L., et al. (2009). Experience of diffusion tensor imaging and $1 \mathrm{H}$ spectroscopy for outcome prediction in severe traumatic brain injury: Preliminary results. Critical Care Medicine, 37, 1448-1455.

Trivedi, M. A., Ward, M. A., Hess, T. M., Gale, S. D., Dempsey, R. J., Rowley, H. A., et al. (2007). Longitudinal changes in global brain volume between 79 and 409 days after traumatic brain injury: Relationship with duration of coma. Journal of Neurotrauma, 24(5), 766-771.

Uzan, M., Albayram, S., Dashti, S. G., Aydin, S., Hanci, M., \& Kuday, C. (2003). Thalamic proton magnetic resonance spectroscopy in vegetative state induced by traumatic brain injury. Journal of Neurolology, Neurosurgery and Psychiatry, 74, 33-38.

Voss, H. U., Uluç, A. M., Dyke, J. P., Watts, R., Kobylarz, E. J., McCandliss, B. D., et al. (2006). Possible axonal regrowth in late recovery from the minimally conscious state. The Journal of Clinical Investigation, 116(7), 1823-1825.

Wedekind, C., Fischbach, R., Pakos, P., Terhaag, D., \& Klug, N. (1999). Comparative use of magnetic resonance imaging and electrophysiologic investigation for the prognosis of head injury. Journal of Trauma, 47, 44-49.

Weiss, N., Galanaud, D., Carpentier, A., Naccache, L., \& Puybasset, L. (2007). Clinical review: Prognostic value of magnetic resonance imaging in acute brain injury and coma. Critical Care, 11, 230.

Wood, S. J., Berger, G., Velakoulis, D., Phillips, L. J., McGorry, P. D., Yung, A. R., et al. (2003). Proton magnetic resonance spectroscopy in first episode psychosis and ultra high-risk individuals. Schizophrenia Bulletin, 29, 831-843.

Xu, J., Rasmussen, I. A., Lagopoulos, J., \& Haberg, A. (2007). Diffuse axonal injury in severe traumatic brain injury visualized using high-resolution diffusion tensor imaging. Journal of Neurotrauma, 24, 753-765.

Yanagawa, Y., Tsushima, Y., Tokumaru, A., Un-no, Y., Sakamoto, T., Okada, Y., et al. (2000). A quantitative analysis of head injury using $\mathrm{T} 2 *$-weighted gradient-echo imaging. Journal of Trauma, 49, 272-277. 